\title{
The importance of the false-negative rate to validate a staging protocol for non-small cell lung cancer
}

\author{
Carme Obiols $^{1}$, Sergi Call ${ }^{1,2}$, Ramon Rami-Porta ${ }^{1,3}$ \\ ${ }^{1}$ Department of Thoracic Surgery, Hospital Universitari MútuaTerrassa, University of Barcelona, Terrassa, Spain; ${ }^{2}$ Department of Morphological \\ Sciences, School of Medicine, Autonomous University of Barcelona, Bellaterra, Spain; ${ }^{3}$ Network of Centers for Biomedical Research in Respiratory \\ Diseases (CIBERES) Lung Cancer Group, Terrassa, Spain \\ Correspondence to: Carme Obiols, MD, PhD, FECTS. Department of Thoracic Surgery, Hospital Universitari MútuaTerrassa, Plaza Dr. Robert 5, \\ 08221 Terrassa, Barcelona, Spain. Email: cobiols@mutuaterrassa.cat. \\ Provenance: This is an invited article commissioned by the Academic Editor Dr. Chenyang Dai (Department of Thoracic Surgery, Shanghai \\ Pulmonary Hospital, School of Medicine, Tongji University, Shanghai, China). \\ Comment on: Verdial FC, Madtes DK, Hwang B, et al. Prediction Model for Nodal Disease Among Patients With Non-Small Cell Lung Cancer. Ann \\ Thorac Surg 2019;107:1600-6.
}

Submitted Jun 29, 2019. Accepted for publication Jul 12, 2019.

doi: $10.21037 /$ tlcr.2019.07.04

View this article at: http://dx.doi.org/10.21037/tlcr.2019.07.04

First of all, we would like to congratulate Dr. Verdial et al. for their recently published article entitled "A prediction model for nodal disease among patients with non-small cell lung cancer" (1). Dr. Verdial and co-workers have analyzed their experience in mediastinal nodal staging for non-small cell lung cancer (NSCLC), based on the recommendations of the current guidelines, in order to find out a better model to predict nodal disease and reduce the need of invasive staging procedures.

American and European guidelines for mediastinal lymph node staging recommend pathologic certification of mediastinal involvement in the following situations: abnormal hilar or mediastinal lymph nodes $[\geq 1 \mathrm{~cm}$ on computed tomography (CT) or increased uptake on positron emission tomography (PET) or PET-CT], tumours $>3 \mathrm{~cm}$ or central tumours. Other characteristics, such as adenocarcinoma cell type or high maximum standardized uptake (SUVmax) value of the primary tumour, are also mentioned in guidelines as factors increasing the risk of lymph node involvement $(2,3)$.

Actually, these clinical situations described above have different probabilities of mediastinal nodal disease (4). For example, Lee et al. (5) observed that the prevalence of occult mediastinal metastasis in clinical (c) stage I central tumours (located in the two internal thirds of the thorax) was $21.6 \%$. The prevalence of mediastinal disease in $\mathrm{cN} 1$ tumours varies from $26 \%$, in a prospective multicenter study by Decaluwé et al. (6), to $40.7 \%$, in a series of tumours staged with video-assisted mediastinoscopic lymphadenectomy (VAMLA) published by Call et al. (7). This last publication is useful to introduce the concept that the more intensive the exploration, the higher the rate of occult N2 disease found (8). Also, the combination of clinical, radiological and laboratory tests may increase the likelihood of identifying mediastinal involvement. This is the case of Koike et al. who observed a prevalence of $34 \%$ of mediastinal metastases when combining age, preoperative serum carcinoembryonic antigen (CEA) level, tumour size and consolidation/tumour ratio on high resolution CT (9). These situations illustrate the difficulty of detecting preoperatively N2 disease and its heterogeneity.

Indeed, the objective of guidelines on preoperative mediastinal staging is to detect N2 disease before lung resection to better stratify patient's prognosis and offer the best treatment strategy, which may include chemotherapy (ChT) or chemoradiotherapy followed or not by surgery, according to the consensual decision of the multidisciplinary committee. As the authors of the article comment on, although induction and adjuvant ChT seem to be associated with similar survival, completion of the whole treatment protocol is more frequently achieved when induction treatment is administered (10). Moreover, 
the authors suggest that the importance of mediastinal staging is to identify multistation N2 disease because these patients will not benefit from surgery. But if the therapeutic plan is not going to change or if it will change only when multistation N2 is detected, then the staging strategy and guidelines should change. Studies showing better prognosis in single station or unsuspected N2 disease are validated with a systematic nodal dissection $(11,12)$. If the objective of preoperative guidelines is focused on detecting the subgroup of patients with multistation involvement (to avoid a futile surgery), a thorough exploration of the mediastinum is needed, probably with a transcervical lymphadenectomy, to offer the highest certainty in the identification of nodal involvement, in terms of number of nodes and stations involved $(7,13)$.

Classically, a pathologic (p) N2 rate of less than $10 \%$ is considered a factor of good quality of the staging protocol (3). Assuming that preoperative mediastinal staging guidelines have the objective of detecting N2 disease preoperatively, it is important not only to reduce the false positive rate of the protocol, but also its false negative rate. Dr. Verdial et al., with their proposed model, based on radiographic and metabolic studies (tumour size, central tumour, hilar/ mediastinal lymphadenopathies, SUVmax of the primary tumour and of the hilar/mediastinal lymph nodes), try to reduce the use of invasive tests that can cause discomfort or serious risks to the patient. Indeed, complication rate for endosonography techniques is low (around $2 \%$ ), and for surgical exploration of the mediastinum it varies from $2 \%$ (for mediastinoscopy) to 4-9\% (for VAMLA) (14). These techniques are usually indicated following a sequence in which the less invasive exploration is performed as a first step, followed by a more invasive exploration to validate negative results. Although not free of risks, these techniques can avoid an unnecessary surgery, which is associated to a complication rate ranging from $18 \%$ to $35 \%(15,16)$, and also give the opportunity of setting a multimodality treatment.

Finally, when evaluating a staging protocol, it is important to define the gold standard that will validate the negative results. In the article by Verdial et al., the median of lymph nodes sampled was 1 (range, $0-3$ ) hilar and 4 (range, 1-8) mediastinal nodes. Although the subanalysis of the population with 3 or more lymph nodes sampled did not observe any changes in their predictive model, the sample size was reduced. Ideally, systematic nodal dissection is the most accurate lymphadenectomy to verify the false-negative and the false-positive rate (referred by the authors as the proportion of patients without nodal disease but presenting with some radiologic or metabolic indication for an invasive staging procedure), especially when the objective of the study is to try to modify an established protocol.

In conclusion, Dr. Verdial et al. have shown their experience and results in mediastinal staging based on their daily clinical practice, with the objective to create a prediction model for nodal disease and reduce the falsepositive rate of the staging protocol. Besides reducing the number of invasive explorations, it is also important to reduce the false negative rate, to avoid unnecessary lung resections and give the chance of receiving the appropriate oncological treatment for a locally advanced lung cancer. Therefore, we encourage Dr. Verdial et al. to continue their work to validate their results with a higher number of patients, but also focusing on the false negative rate of their staging protocol.

\section{Acknowledgments}

None.

\section{Footnote}

Conflicts of Interest: The authors have no conflicts of interest to declare.

Ethical Statement: The authors are accountable for all aspects of the work in ensuring that questions related to the accuracy or integrity of any part of the work are appropriately investigated and resolved.

\section{References}

1. Verdial FC, Madtes DK, Hwang B, et al. Prediction Model for Nodal Disease Among Patients With Non-Small Cell Lung Cancer. Ann Thorac Surg 2019;107:1600-6.

2. Silvestri GA, Gonzalez AV, Jantz MA, et al. Methods for staging non-small cell lung cancer: Diagnosis and management of lung cancer, 3rd ed: American College of Chest Physicians evidence-based clinical practice guidelines. Chest 2013;143:e211S-e250S.

3. De Leyn P, Dooms C, Kuzdzal J, et al. Revised ESTS guidelines for preoperative mediastinal lymph node staging for non-small-cell lung cancer. Eur J Cardiothorac Surg 2014;45:787-98.

4. Obiols C, Call S. Pros: should a patient with stage IA non-small cell lung cancer undergo invasive mediastinal 
staging? Transl Lung Cancer Res 2016;5:247-50.

5. Lee PC, Port JL, Korst RJ, et al. Risk factors for occult mediastinal metastases in clinical stage I non-small cell lung cancer. Ann Thorac Surg 2007;84:177-81.

6. Decaluwé H, Dooms C, D'Journo XB, et al. Mediastinal staging by videomediastinoscopy in clinical N1 non-small cell lung cancer: a prospective multicentre study. Eur Respir J 2017. doi: 10.1183/13993003.01493-2017.

7. Call S, Obiols C, Rami-Porta R, et al. Video-Assisted Mediastinoscopic Lymphadenectomy for Staging Non-Small Cell Lung Cancer. Ann Thorac Surg 2016;101:1326-33.

8. Detterbeck F. What to do with "Surprise" N2?: intraoperative management of patients with non-small cell lung cancer. J Thorac Oncol 2008;3:289-302.

9. Koike T, Koike T, Yamato Y, et al. Predictive risk factors for mediastinal lymph node metastasis in clinical stage IA non-small-cell lung cancer patients. J Thorac Oncol 2012;7:1246-51.

10. Felip E, Rosell R, Maestre JA, et al. Preoperative chemotherapy plus surgery versus surgery plus adjuvant chemotherapy versus surgery alone in early-stage nonsmall-cell lung cancer. J Clin Oncol 2010;28:3138-45.

Cite this article as: Obiols C, Call S, Rami-Porta R. The importance of the false-negative rate to validate a staging protocol for non-small cell lung cancer. Transl Lung Cancer Res 2019;8(Suppl 4):S400-S402. doi: 10.21037/tlcr.2019.07.04
11. Cerfolio RJ, Bryant AS. Survival of patients with unsuspected N2 (stage IIIA) nonsmall-cell lung cancer. Ann Thorac Surg 2008;86:362-6; discussion 366-7.

12. Obiols C, Call S, Rami-Porta R, et al. Survival of patients with unsuspected pN2 non-small cell lung cancer after an accurate preoperative mediastinal staging. Ann Thorac Surg 2014;97:957-64.

13. Zieliński M, Hauer L, Hauer J, et al. [Transcervical Extended Mediastinal Lymphadenectomy (TEMLA) for staging of non-small-cell lung cancer (NSCLC)]. Pneumonol Alergol Pol 2011;79:196-206.

14. Rami-Porta R, Call S, Dooms C, et al. Lung cancer staging: a concise update. Eur Respir J 2018. doi: 10.1183/13993003.00190-2018.

15. Salati M, Brunelli A, Decaluwe H, et al. Report from the European Society of Thoracic Surgeons Database 2017: patterns of care and perioperative outcomes of surgery for malignant lung neoplasm. Eur J Cardiothorac Surg 2017;52:1041-8.

16. Duque JL, Rami-Porta R, Almaraz A, et al. Risk factors in bronchogenic carcinoma surgery. Arch Bronconeumol 2007;43:143-9. 